\title{
Accuracy Analysis of the Aerosol Backscatter Coefficient Profiles Derived from the CYY-2B Ceilometer
}

\author{
Lei Liu ${ }^{1},{ }^{1}$ Ting Zhang, ${ }^{2}$ Yi Wu, ${ }^{3}$ Qi Wang, ${ }^{1}$ and Taichang Gao ${ }^{1}$ \\ ${ }^{1}$ College of Meteorology and Oceanography, National University of Defense Technology, Nanjing, Jiangsu 211101, China \\ ${ }^{2}$ Hebei Provincial Meteorological Bureau, CMA, Shijiazhuang, Hebei 050000, China \\ ${ }^{3}$ Nanjing Meteorological Bureau, CMA, Nanjing, Jiangsu 210019, China \\ Correspondence should be addressed to Lei Liu; liuleidll@gmail.com
}

Received 20 March 2018; Revised 11 June 2018; Accepted 25 June 2018; Published 8 July 2018

Academic Editor: Alastair Williams

Copyright $\odot 2018$ Lei Liu et al. This is an open access article distributed under the Creative Commons Attribution License, which permits unrestricted use, distribution, and reproduction in any medium, provided the original work is properly cited.

\begin{abstract}
Ceilometers are originally designed for cloud base height monitoring. Since a few years, the number of ceilometers available worldwide is rapidly increasing, and these simple backscatter lidars are investigated to be used for aerosol research. This study presents an assessment of the potential of CYY-2B ceilometer for the quantitative retrieval of aerosol properties. The signal-tonoise ratio of the ceilometer is calculated, and the effective height of inversion is determined. It is shown that the effective height of the ceilometer for backscatter coefficient profile inversion is $3-4 \mathrm{~km}$ at night and about $1.5-2 \mathrm{~km}$ during the day, which is lower than that of the micropulse lidar (MPL) system. The accuracy of the backscatter coefficient profiles derived from the CYY-2B ceilometer is analyzed by using the Vaisala CL51 ceilometer, MPL, forward scatter visibility instrument, and aerosol optical depth (AOD) dataset from aerosol robotic network (AERONET). Spectral conversions of the ceilometer's and lidar's data are performed using the Ångström exponent estimated by AERONET measurements. A good agreement is found between two ceilometers and the MPL lidar in backscatter coefficient profiles inversion. The AODs agree well with the AERONET AODs during the observation period of small AODs. However, for the period of large AODs, the results are approximately $50 \%-60 \%$ of AERONET AODs. The limited range of extinction integration is the main cause of this problem.
\end{abstract}

\section{Introduction}

The vertical profiles of aerosol parameters are of great value in the research on cloud-aerosol interaction, aerosol transport, air pollution, and human health. Lidars are recognized as effective tools for remote sensing of aerosol profiles; however, they are quite expensive because of their complexity systems. What is more, their number is limited, and many of them are operated by research institutes only occasionally or during dedicated field campaigns. In recent years, some researchers proposed to use ceilometers to retrieve aerosol vertical profiles [1-5] and served as an effective supplement to lidar network [5]. In China, a large number of ceilometers have been installed in civilian airports and some meteorological stations. According to reports, the number of civil airports in domestic will reach 260 in the year 2020. It is of positive significance to improve the observation level of aerosol network by studying the accuracy of aerosol vertical profiles using ceilometers in China.
Ceilometers are single-wavelength backscatter lidars with the emitted wavelength in the near infrared between 900 and $1100 \mathrm{~nm}$. They are traditionally used only to measure cloud base height [6]. The pulse energy of the laser is sufficiently low to allow eye-safe operation resulting in a very low signal-to-noise ratio which is in particular true for daytime measurements [7]. Therefore, the aerosol profiles derived from ceilometers should have greater limitation compared with the lidars. Jin et al. [8] proposed a method of jointly retrieving the aerosol extinction profiles by ceilometer and sky-radiometer. Binietoglou et al. [9] proposed to calibrate the ceilometer signal with long-time (more than 2-3 hours) backscatter of atmospheric molecules to obtain more reliable and accurate inversion results. Wiegner and Geiß [10] provided an absolute calibration of the ceilometer to improve the aerosol detection accuracy. Recently, some researchers compared aerosol backscatter coefficient profiles retrieved by ceilometers and lidars and assessed the potential 
of ceilometers for the quantitative retrieval of aerosol properties $[7,11,12]$.

In this paper, we use data of a ceilometer CYY-2B to discuss the accuracy of aerosol backscatter profile inversion. In Section 2, we briefly describe the specifications of the instruments used in this study. The data retrieval methods are also explained. Then, the effective height of inversion is analyzed in Section 3. And, the accuracy of the backscatter profiles derived from the ceilometer is discussed in detail. Finally, the work is concluded in Section 4.

\section{Data and Inversion Method}

2.1. Specifications of the Instruments. The ceilometer used in this study is CYY-2B. It is a biaxial ceilometer produced by CAMA (Luoyang), an environment monitoring limited company that operates at the Chinese Meteorological Administration (CMA), Beijing Observatory Station $\left(39.813,788^{\circ} \mathrm{N}, 116.480,059^{\circ} \mathrm{E}, 55 \mathrm{~m}\right.$ ASL.) from November 1 , 2011, to May 12, 2012. According to the manufacturer, CYY2B ceilometer equipped with an InGaAs pulsed diode laser emitting at $905 \pm 10 \mathrm{~nm}$ with an energy per pulse of $22 \mu \mathrm{J}$. The emission frequency is $5 \mathrm{kHz}$, while the pulse duration is $100 \mathrm{~ns}$. The backscattered signal profiles typically have a vertical resolution of $5 \mathrm{~m}$ and a temporal resolution of $1 \mathrm{~min}$. The instrument has a specified range of $10 \mathrm{~km}$ and full overlap at around $500 \mathrm{~m}$. Overlap correction functions are provided by the manufacturer down to approximately $250 \mathrm{~m}$. Generally, the CYY-2B ceilometer can provide raw backscattered signals and the determination of cloud base height.

The other ceilometer used is the Vaisala CL51, which uses a $910 \pm 10 \mathrm{~nm}$ diode with a pulse frequency of $6.5 \mathrm{kHz}$ as an optical source. The energy per emitted pulse is $3 \mu \mathrm{J}$. It can measure laser backscatter above ground up to a maximum height of $15 \mathrm{~km}$ with a range resolution of $10 \mathrm{~m}$. Typically the minimum height of CL51-ceilometer-derived aerosol profiles is approximately $200 \mathrm{~m}$ [1]. The output profiles are already corrected for incomplete overlap, but the function itself is unknown to the user. The locations of ceilometer CL51 and CYY-2B are about $30 \mathrm{~m}$ away from each other.

The lidar used as a reference in this study is the standard NASA/Micro Pulse Lidar (MPL-4B-532, Sigma Space Corp.). The MPL-4B-532 system is configured in a zenith monostatic coaxial alignment and is based on an eye-safe pulsed Nd:YLF laser emitting at $532 \mathrm{~nm}$. The energy per emitted pulse is $6-10 \mu \mathrm{J}$, while the repetition rate is $2.5 \mathrm{kHz}$. Backscattered signals are registered at 1 min integrated time and $15 \mathrm{~m}$ vertical resolution, with a measurement range of $30 \mathrm{~km}$. Because of instrumental constraints, the lowest recoverable altitude is about $400 \mathrm{~m}$ [13]. The MPL lidar was installed in the middle of the ceilometer CL51 and CYY-2B with a distance of about $15 \mathrm{~m}$ from each location.

In addition, the spectral aerosol optical thickness at $440 \mathrm{~nm}, 675 \mathrm{~nm}, 870 \mathrm{~nm}$, and $1020 \mathrm{~nm}$ derived from AERONET [14] sun photometer measurements over the region is used. The AERONET is a network of ground-based sun photometers which measure atmospheric aerosol properties. The measurement system is a solar-powered CIMEL Electronique $318 \mathrm{~A}$ spectral radiometer. The data of AERONET are mainly used for two aspects. One is to convert the wavelength of the extinction coefficient profiles of two ceilometers so as to compare with the extinction coefficients retrieved from the MPL. The second is to do comparisons with the aerosol optical depth derived from the ceilometers and the MPL lidar.

2.2. Method of Aerosol Backscatter Coefficient Profile Inversion by Ceilometer. The return signal of the ceilometer first needs to be corrected for the $r^{2}$-geometrical attenuation and the overlap factor which can be expressed by:

$$
X(r)=C \beta(r) T^{2}(r)=\frac{S(r) \times r^{2}}{O_{c}(r)},
$$

where $S(r)$ is the original return signal, $C$ is the instrument parameter, $O_{c}(r)$ is the ceilometer overlap function, $\beta(r)$ is the backscatter coefficient, and it includes the backscattering coefficient of air molecules $\beta_{\mathrm{m}}$ and that of the aerosols $\beta_{\mathrm{a}}$, and $T(r)$ is the atmospheric transmittance.

Aerosol backscatter coefficient profiles, $\beta_{\mathrm{a}}(r)$, can be derived using the method of Fernald [15]. The lidar ratio $S_{\mathrm{a}}$ for the retrievals depends on the size distribution and refractive index of aerosol particles. In this paper, it is assumed by default to be equal to $50 \mathrm{sr}$. The obtained $\beta_{\mathrm{a}}(r)$ is substituted in a formula $\sigma_{\mathrm{a}}(r)=\beta_{\mathrm{a}}(r) \times S_{\mathrm{a}}$ to calculate the extinction profile $\sigma_{\mathrm{a}}(r)$. It is worth noting that the assumption of a constant lidar ratio can lead to errors in the derived aerosol extinction and backscattering profiles. In previous studies [8], it is shown that, if the aerosol optical depth value is smaller than 0.2 , the retrieval errors on the backscattering coefficients do not exceed $15 \%$ according to the $\pm 30 \%$ variation of the lidar ratios, whereas the errors on the extinction coefficients exceed $30 \%$. In the iterative solution, the position of reference height should be determined first. Normally, the reference height is chosen from the upper atmosphere, which almost does not contain aerosol particles. However, the detection capability of the ceilometer is difficult to reach this height. This study adopts the approximate uniform regional assumption method proposed by Tao et al. [16]. It is assumed that the ceilometer has an aerosol uniform mixing zone in the detection range, and $\beta_{\mathrm{a}}(r) / \beta_{\mathrm{m}}(r)$ is approximately a constant value in this area. Thus, $\ln \left(X(r) / \beta_{\mathrm{m}}(r)\right)$ is linear with the range, and the aerosol extinction coefficient in this layer can be obtained by the slope method:

$$
\sigma_{\mathrm{a} 0}(r)=-\frac{1}{2} \frac{d\left[\ln \left(X(r) / \beta_{\mathrm{m}}(r)\right)\right]}{d r}-\sigma_{\mathrm{m}}(r) .
$$

This aerosol extinction coefficient is the boundary value of the Fernald method. The specific position of reference height can be determined by calculating the minimum residual sum of squares of all the measured data in this section (generally $2 \mathrm{~km}-5 \mathrm{~km}$ ) deviating from the fitting line according to the least square method.

\section{Results and Discussion}

3.1. Effective Height of Ceilometer for Backscatter Coefficient Profile Inversion. One of the important parameters related 


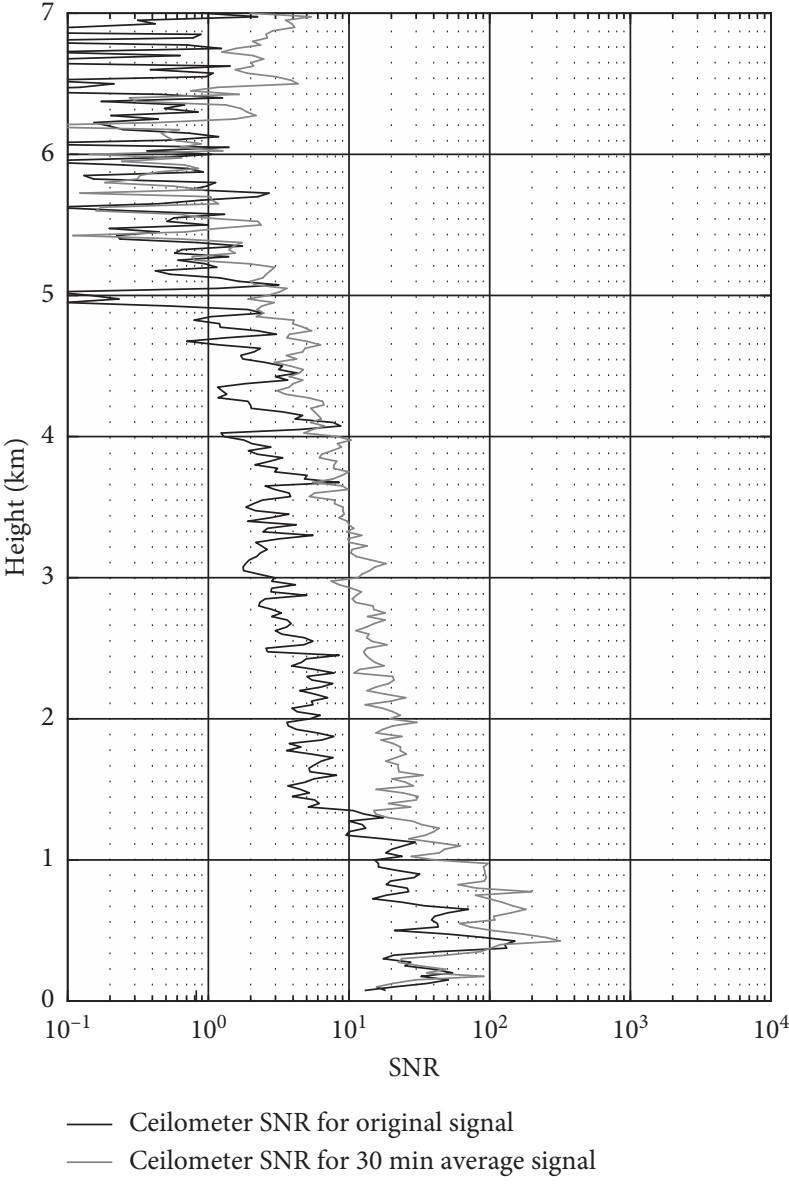

(a)

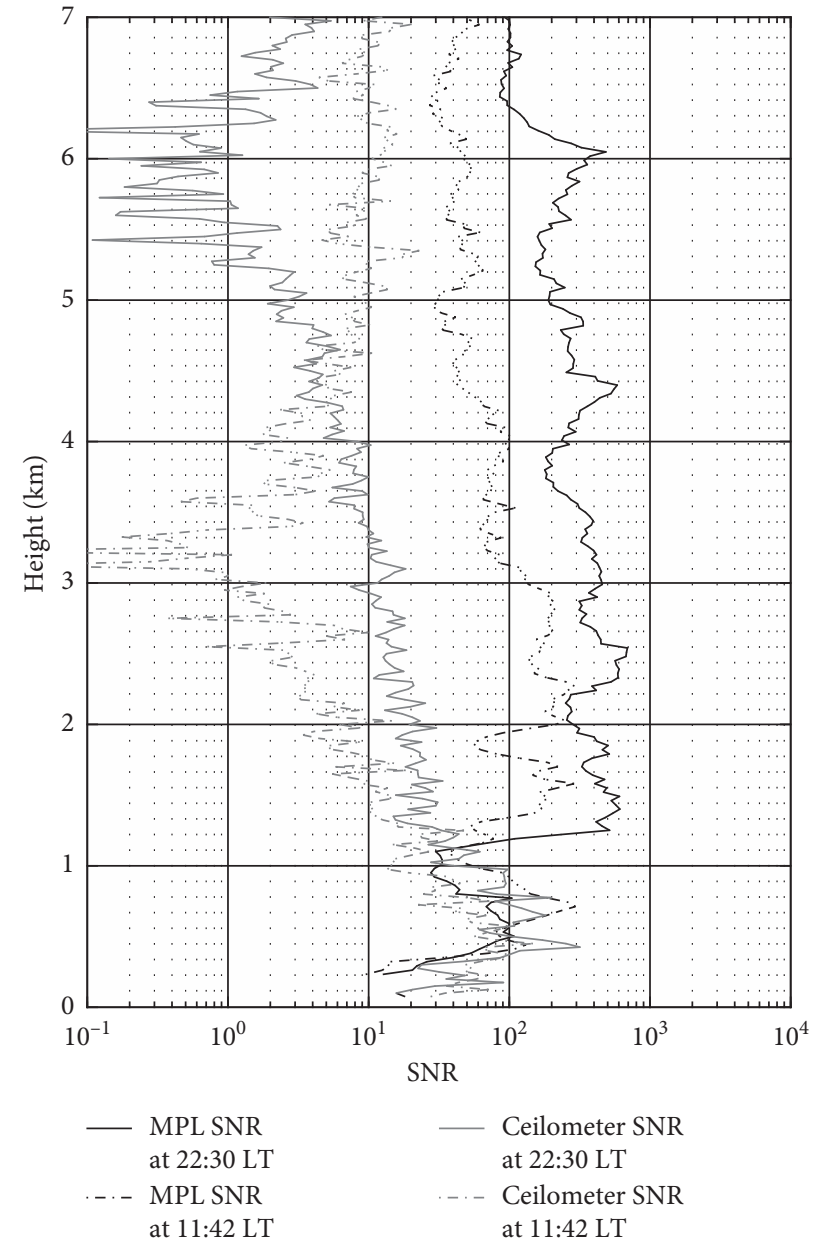

(b)

FIgure 1: The SNR for the CYY-2B ceilometer and the MPL as a function of altitude.

to ceilometer retrievals is the effective height which means the maximum range where aerosol remote sensing is possible. Research shows the effective height is related to the signal-to-noise ratio (SNR). In this study, we use the method described by Xie and Zhou [17], which allows us to calculate SNR based on the range-corrected signal.

Firstly, the range-corrected ceilometer backscattering signal $X(r)$ is calculated from (1). Then, the fitting coefficient $a$ and $b$ are obtained by the linear fitting of $\ln X(r)$ and distance $r$ with $n+1$ data points. The true signal $n_{\mathrm{s}}(r)$ and the corresponding noise $n_{\mathrm{n}}(r)$ can be obtained by the following equation:

$$
\begin{aligned}
& n_{\mathrm{s}}(r)=\frac{1}{n+1} \times \sum_{j=i-(n / 2)}^{i+(n / 2)}\left(a+b r_{j}\right), \\
& n_{\mathrm{n}}(r)=\frac{1}{n+1} \times \sum_{j=i-(n / 2)}^{i+(n / 2)}\left|\ln \left[X\left(r_{j}\right)\right]-\left[a+b r_{j}\right]\right| .
\end{aligned}
$$

The last step is to calculate the SNR which equals to the ratio of the signal $n_{\mathrm{s}}(r)$ to the noise $n_{\mathrm{n}}(r)$.

The raw range resolution of CYY-2B ceilometer is $2.5 \mathrm{~m}$. According to Xie and Zhou [17], the fitting points $n$ should be set in order to satisfy both the assumption of atmospheric uniformity and discrimination of SNR value, resulting in SNR data with $100 \mathrm{~m}$ resolution. The data resolution of the MPL is $15 \mathrm{~m}$ and $n$ is set to 7 ; therefore, the SNR data resolution is about $105 \mathrm{~m}$. The ceilometer SNRs of the original signal and the $30 \mathrm{~min}$ average signal are calculated, respectively (Figure $1(\mathrm{a})$ ).

We see that the SNR can be improved by accumulating the original signal of the laser ceilometer. The SNR of the original signal is gradually less than 10 (this value is the minimum requirement for the SNR that can be used to retrieve aerosol backscatter coefficients $[4,17])$ at $1.5 \mathrm{~km}$, but the available height of it can reach 3-4 km after accumulating for $30 \mathrm{~min}$. For comparison, the SNR for the MPL signal is shown, too. As seen in Figure 1(b), due to the higher receiver efficiency, the SNR of the MPL is much better than the laser ceilometer. For both of two devices, the SNR at night is better than that at daytime. For the CYY-2B laser ceilometer, the effective height of ceilometer for backscatter profile inversion can be $3-4 \mathrm{~km}$ at night and $1.5-2 \mathrm{~km}$ during the daytime. It means that the ceilometer signal is too noisy and is only capable to measure the signal backscattered from particles in a low range. 


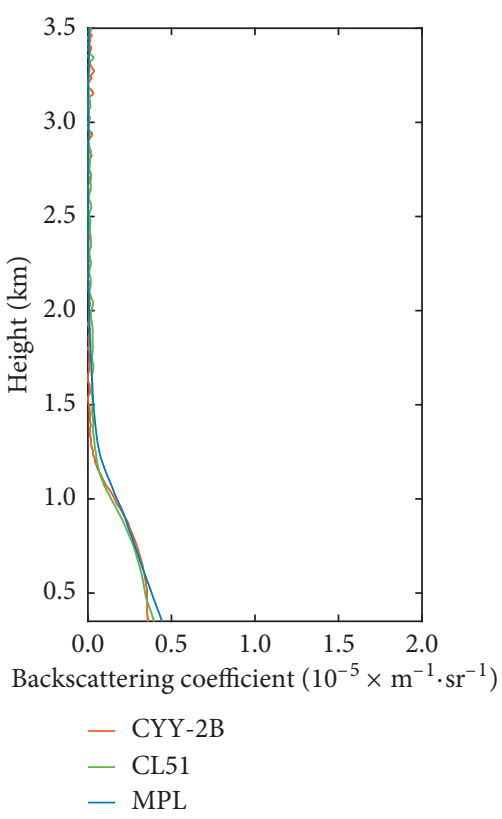

(a)

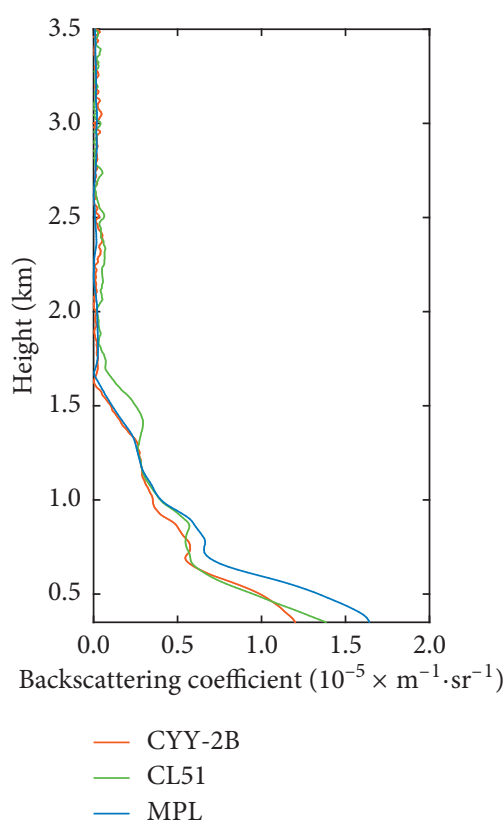

(b)

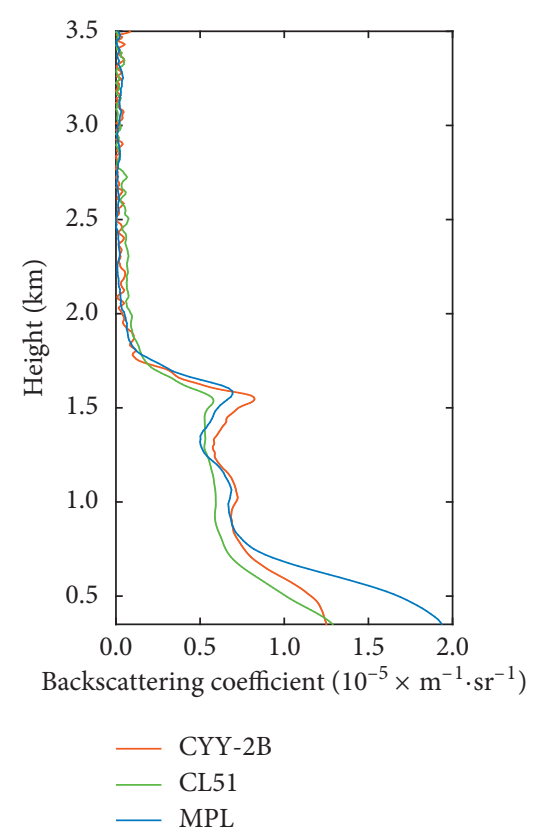

(c)

Figure 2: Differences in extinction coefficient profiles derived from two ceilometers and the MPL. (a) 4-Dec-2011 10:59:52. (b) 15-Feb-2012 10:59:48. (c) 27-Feb-2012 13:53:54.

3.2. Comparison of the Aerosol Optical Properties Obtained from Different Instruments. In order to compare the retrievals of both the MPL and the ceilometers, a spectral conversion is needed when different wavelengths are used. The backscatter coefficient profiles derived from ceilometer CYY-2B and CL51 can be conversed to $532 \mathrm{~nm}$ according to the following equations:

$$
\begin{aligned}
\beta\left(\lambda_{1}, r\right) & =\beta\left(\lambda_{2}, r\right) \times e^{-\ln \left(\lambda_{1} / \lambda_{2}\right) \times C}, \\
C & =\frac{\ln \tau_{\lambda_{2}}-\ln \tau_{\lambda_{1}}}{\ln \lambda_{1}-\ln \lambda_{2}},
\end{aligned}
$$

where $C$ is the Angström exponent and $\lambda_{1}$ and $\lambda_{2}$ are the emitted laser wavelengths $\left(\lambda_{1}=0.532 \mu \mathrm{m}, \lambda_{2}=0.905\right.$ or $\left.0.91 \mu \mathrm{m}\right)$.

The optical thickness $\tau_{\lambda}$ at wavelengths $532 \mathrm{~nm}$ and $905 \mathrm{~nm}$ $(910 \mathrm{~nm})$ does not exist in the AERONET product, so it needs to be calculated from the Ångström formula $\left(\tau_{\lambda}=b \lambda^{-C}\right)$. Where $\beta$ is the optical thickness at wavelength $\lambda=1 \mu \mathrm{m}$, and the optical thickness at $1020 \mathrm{~nm}$ is approximately equal to that at $1 \mu \mathrm{m}$ in the AERONET product; that is, $b \approx \tau_{1.020}$. The Angström exponent $C$ can be calculated using (5). If $\tau_{0.532}$ is expected, the optical thickness at $\lambda_{1}=0.87 \mu \mathrm{m}$ and $\lambda_{1}=0.44 \mu \mathrm{m}$ in the AERONET product will be selected. Depending on $C$ and $b$, the $\tau_{0.532}$ is given by Ångström formula. In the same way, the optical thickness at $\lambda_{1}=1.020 \mu \mathrm{m}$ and $\lambda_{2}=0.87 \mu \mathrm{m}$ will be selected to calculate $\tau_{0.905}$ or $\tau_{0.91}$. When performing the spectral conversion, the parameter $C$ is firstly computed using $\tau_{0.532}$ and $\tau_{0.905}\left(\tau_{0.91}\right)$ according to $(5)$, and then the aerosol backscatter coefficient profiles derived at $905 \mathrm{~nm}(910 \mathrm{~nm})$ will be conversed to $532 \mathrm{~nm}$ by using the conversion (4).

In Figure 2, we present the results of the comparison of backscatter coefficient profiles obtained by the MPL (at
$532 \mathrm{~nm}$ ), CYY-2B ceilometer (converted to $532 \mathrm{~nm}$ data), and CL51 ceilometer (converted to $532 \mathrm{~nm}$ data) instruments. According to the AODs data obtained by AERONET, the optical thickness of aerosol in December 24, 2011, was about 0.2 (at $532 \mathrm{~nm}$, the latter AODs in this paper are all at $532 \mathrm{~nm}$ band without further explanation), and visibility was about $20 \mathrm{~km}$. From Figure 2(a), we see that, in small aerosol content condition, the retrieved backscatter vertical profiles converted to $532 \mathrm{~nm}$ by both two ceilometers is quite satisfactory with that derived from MPL. As it can be observed in Figures 2(b) and 2(c), the backscatter coefficient profiles derived from the ceilometers and the MPL have been much more varied when the visibility is low on 15 February (the optical thickness of aerosol was about 0.7 ) and 27 February (the optical thickness of aerosol was about 1.6). Besides, although there are differences between them below $2000 \mathrm{~m}$, the trends are the same. On 27 February 2012, the MPL system detected two aerosol layers around $1200 \mathrm{~m}$ and $1600 \mathrm{~m}$. From Figure 2(c), we can see that the aerosol layers recorded by both ceilometers and MPL were generally in good agreement. In addition, we note that the backscatter vertical profiles obtained by CL51 and CYY-2B are close, while there are some differences between the two ceilometers and MPL. The difference can be attributed to the errors in the spectral conversion process.

In order to further confirm the accuracy of the aerosol vertical profiles inversion of the two ceilometer instruments, we calculated the extinction coefficients using the conversed backscattering coefficients at $532 \mathrm{~nm}$ for ceilometer CYY-2B and CL51 and the lidar ratio $S_{\mathrm{a}}$ equal to $50 \mathrm{sr}$. Then, the extinction coefficient deduced from the surface meteorological visibility was compared with the near-surface extinction coefficient of the CYY-2B, CL51 laser ceilometer, 


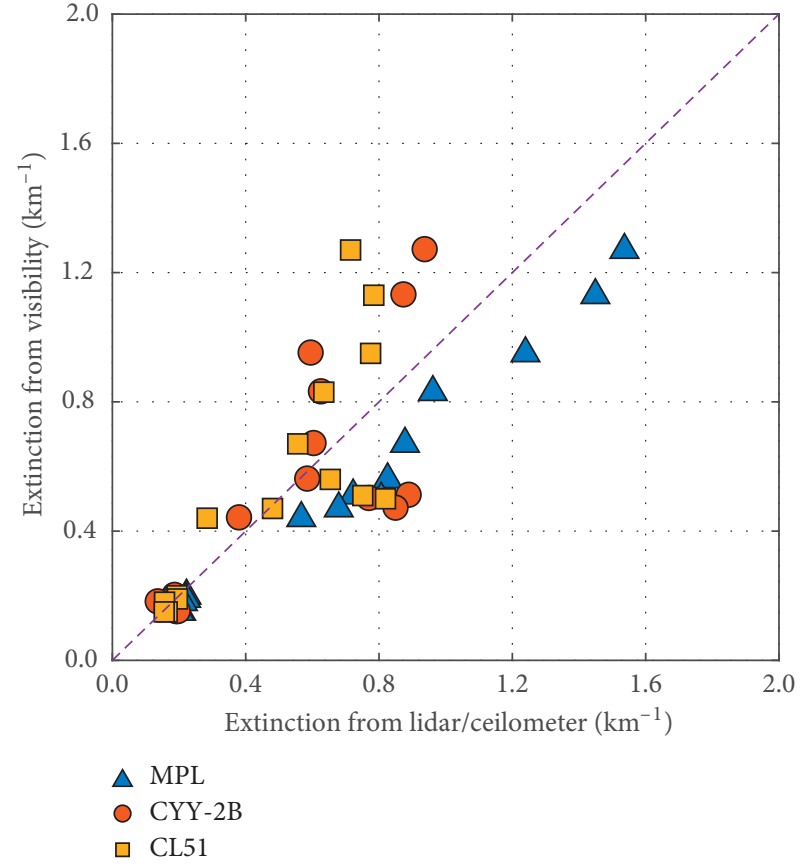

(a)

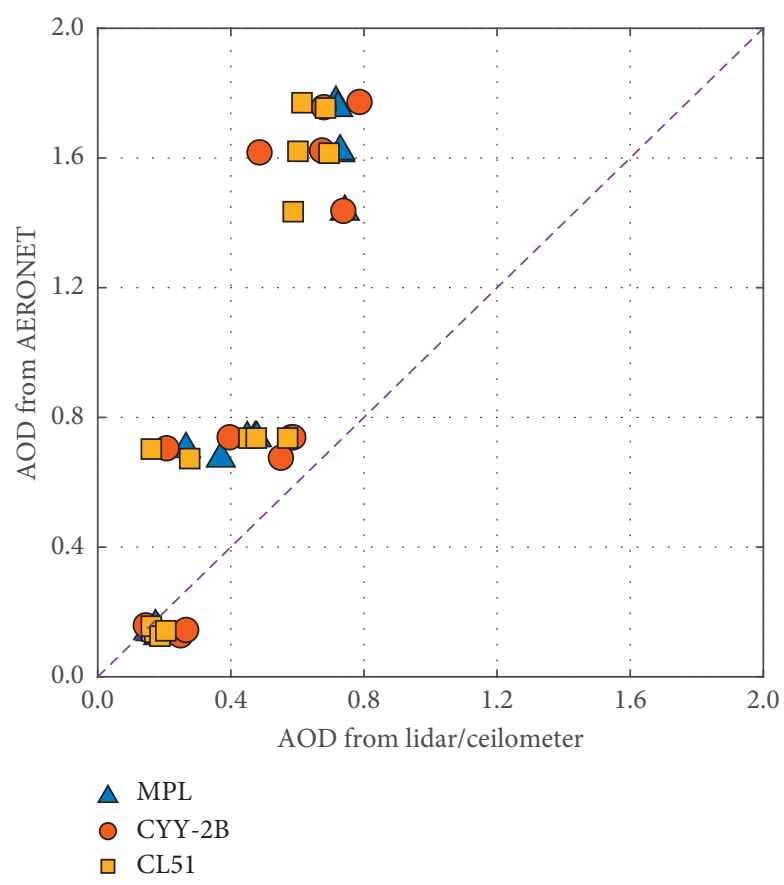

(b)

FIgURE 3: Comparison of extinction coefficient near surface and AOD derived from the ceilometers and the MPL lidar.

and the MPL. The formula for deriving the extinction coefficient from surface meteorological visibility is as follows:

$$
\sigma_{\mathrm{p}}(0.532,0)=\frac{3.912}{V I S}-\sigma_{\mathrm{m}},
$$

where VIS adopts the data observed by a forward-scatter visibility meter and $\sigma_{\mathrm{m}}$ is the surface-level molecular extinction coefficient at the wavelength of $532 \mathrm{~nm}$ which is a function of air temperature and pressure.

The comparison results are shown in Figure 3(a). We can see that, when the visibility of the near ground is good which means the extinction coefficient is small, the result obtained by laser ceilometers and MPL is similar with that derived from the forward-scatter visibility meter. With the decrease of visibility, the result of MPL measurement is larger than that of visibility meter, but the linearity is still good. The differences can be explained by a slightly wrong lidar ratio and the uncertainty of the visibility meter. As can be seen in Figure 3(a), the differences of the extinction coefficients derived from two ceilometers and from the forward-scatter visibility meter are fluctuating with the decrease of visibility. The cause of this phenomenon may be due to its low signalto-noise ratio, and the backscattering coefficient inversion result is not stable enough. In order to achieve more stable results, a longer integral time should be added, such as 3 hours [11], or even more. Further, we compare the aerosol optical thickness obtained by AERONET with that integrated from extinction coefficients of MPL and CYY-2B laser ceilometer. From Figure 3(b), we see that the AODs derived from both ceilometers and lidar agreed well with the sky-radiometer AODs in the case of small optical thickness. In the scatter diagrams, the ceilometer CL51 and CYY-2B
AODs deviate from the equality line as the AERONET AODs increase. Because the aerosol signals of the ceilometers and lidar are limited to a lower height (below $3 \mathrm{~km}$ ), the derived AODs may have been underestimated (the AOD results were approximately $50 \%-60 \%$ of AERONET AODs which is in accordance with the conclusions obtained from the literature [8]) for large AODs. In addition, the two ceilometers operate at a wavelength sensitive to water vapor absorption. AODs derived from the ceilometers are biased because of the uncorrected water vapor absorption effect.

\section{Summary and Conclusions}

In this paper, we showed the capability of the CYY-2B ceilometer to detect aerosol properties. The effective height which is related to SNR is studied and compared with that from MPL. It is shown that use of the CYY-2B ceilometer to measure aerosol vertical profile is limited to the boundary layer because of its small SNR. The typical effective height of the aerosol vertical profiles retrieved from the CYY-2B ceilometer is $3-4 \mathrm{~km}$ at night and about $1.5-2 \mathrm{~km}$ during the day. The aerosol optical properties obtained from the CYY-2B ceilometer are also investigated by different approach comparisons. With the multiband AOD provided by AERONET, the aerosol vertical profiles obtained by ceilometer at $905 \mathrm{~nm}(910 \mathrm{~nm})$ can be conversed to $532 \mathrm{~nm}$, and it can be compared and analyzed with the data from MPL. It is showed that, in general, a good agreement was found in backscatter coefficient profile inversion. The differences may be attributed mainly to an unsatisfactory retrieval of the backscatter-related Angström exponent estimated by AERONET dataset. The AODs derived from 
two ceilmeters and MPL lidar agreed well with the skyradiometer AOD from AERONET during the low AODs observation period. However, in a time period with large AODs, the results were approximately $50 \%-60 \%$ of the AERONET AODs.

In conclusion, our study indicates that, it is possible to use ceilometers to study the boundary layer aerosol structure and derive quantitative information about the backscatter profiles, but they are limited. The capability to determine the mixing layer height of the CYY-2B ceilometer should be analyzed in future. In this paper, we do not correct for the attenuation effect of water vapor absorption for the measurement wavelengths of the CYY-2B and CL51 ceilometer. What is more, it should be pointed out that the data used in this study are only in the Beijing area and only in the cloudless sky. Data in multiple areas and in the different weather conditions need to be analyzed.

\section{Data Availability}

The data used to support the findings of this study are available from the corresponding author upon request.

\section{Conflicts of Interest}

The authors declare that there are no conflicts of interest regarding the publication of this paper.

\section{Acknowledgments}

The authors thank the staff and data providers at the Chinese Meteorological Administration (CMA) Beijing Observatory Station for their assistance. This research was supported by the National Natural Science Foundation of China (Grant no. 41575024).

\section{References}

[1] M. Wiegner, F. Madonna, I. Binietoglou et al., "What is the benefit of ceilometers for aerosol remote sensing? An answer from EARLINET," Atmospheric Measurement Techniques, vol. 7, no. 7, pp. 1979-1997, 2014.

[2] J. Yuan, L. Bu, X. Huang et al., "particulate characteristics during a haze episode based on two ceilometers with different wavelengths," Atmosphere, vol. 7, no. 2, p. 20, 2016.

[3] A.-M. Sundström, T. Nousiainen, and T. Petäjä, "On the quantitative low-level aerosol measurements using ceilometertype lidar," Journal of Atmospheric and Oceanic Technology, vol. 26, no. 11, pp. 2340-2352, 2009.

[4] K. M. Markowicz, P. J. Flatau, A. E. Kardas et al., "Ceilometer retrieval of the boundary layer vertical aerosol extinction structure," Journal of Atmospheric and Oceanic Technology, vol. 25, no. 6, pp. 928-944, 2008.

[5] F. Madonna, F. Amato, J. Vande Hey et al., "Ceilometer aerosol profiling versus Raman lidar in the frame of the INTERACT campaign of ACTRIS," Atmospheric Measurement Techniques, vol. 8, no. 5, pp. 2207-2223, 2015.

[6] A. J. Illingworth, R. J. Hogan, E. J. O’Connor et al., "Cloudnet: continuous evaluation of cloud profiles in seven operational models using ground-based observations," Bulletin of the American Meteorological Society, vol. 88, no. 6, pp. 883-898, 2007.
[7] B. Heese, H. Flentje, D. Althausen et al., "Ceilometer lidar comparison: backscatter coefficient retrieval and signal-tonoise ratio determination," Atmospheric Measurement Techniques, vol. 3, no. 6, pp. 1763-1770, 2010.

[8] Y. Jin, K. Kai, K. Kawai et al., "Ceilometer calibration for retrieval of aerosol optical properties," Journal of Quantitative Spectroscopy and Radiative Transfer, vol. 153, pp. 49-56, 2015.

[9] I. Binietoglou, A. Amodeo, G. D'Amico et al., "Examination of possible synergy between lidar and ceilometer for the monitoring of atmospheric aerosols," in Lidar Technologies, Techniques, and Measurements for Atmospheric Remote Sensing VII, Proceedings of SPIE, p. 818209, Singapore, 2011.

[10] M. Wiegner and A. Geiß, "Aerosol profiling with the Jenoptik ceilometer CHM15kx," Atmospheric Measurement Techniques, vol. 5, no. 8, pp. 1953-1964, 2012.

[11] G. Tsaknakis, A. Papayannis, P. Kokkalis et al., "Intercomparison of lidar and ceilometer retrievals for aerosol and Planetary Boundary Layer profiling over Athens, Greece," Atmospheric Measurement Techniques, vol. 4, no. 6, pp. 1261-1273, 2011.

[12] H. A. McGowan and J. Soderholm, "Laser ceilometer measurements of Australian dust storm highlight need for reassessment of atmospheric dust plume loads," Geophysical Research Letters, vol. 39, no. 2, p. L02804, 2012.

[13] A. Misra, S. N. Tripathi, D. S. Kaul et al., "Study of MPLNETDerived Aerosol Climatology over Kanpur, India, and validation of CALIPSO level 2 version 3 backscatter and extinction products," Journal of Atmospheric and Oceanic Technology, vol. 29, no. 9, pp. 1285-1294, 2012.

[14] B. N. Holben, T. F. Eck, I. Slutsker et al., "AERONET-A federated instrument network and data archive for aerosol characterization," Remote Sensing of Environment, vol. 66, no. 1, pp. 1-16, 1998.

[15] F. G. Fernald, "Analysis of atmospheric lidar observations: some comments," Applied Optics, vol. 23, no. 5, pp. 652-653, 1984.

[16] Z. Tao, Q. Zhang, K. E. Yuan et al., "Retrieving aerosol backscattering coefficient for short range lidar using parameter selection at reference point," Chinese Optics Letters, vol. 8 , no. 8, pp. 732-734, 2010.

[17] C. Xie and J. Zhou, "Method and analysis of calculating signalto-noise ratio in lidar sensing," in Proceedings of SPIE, Optical Technologies for Atmospheric, Ocean, and Environmental Studies, pp. 738-746, Beijing, China, 2005. 

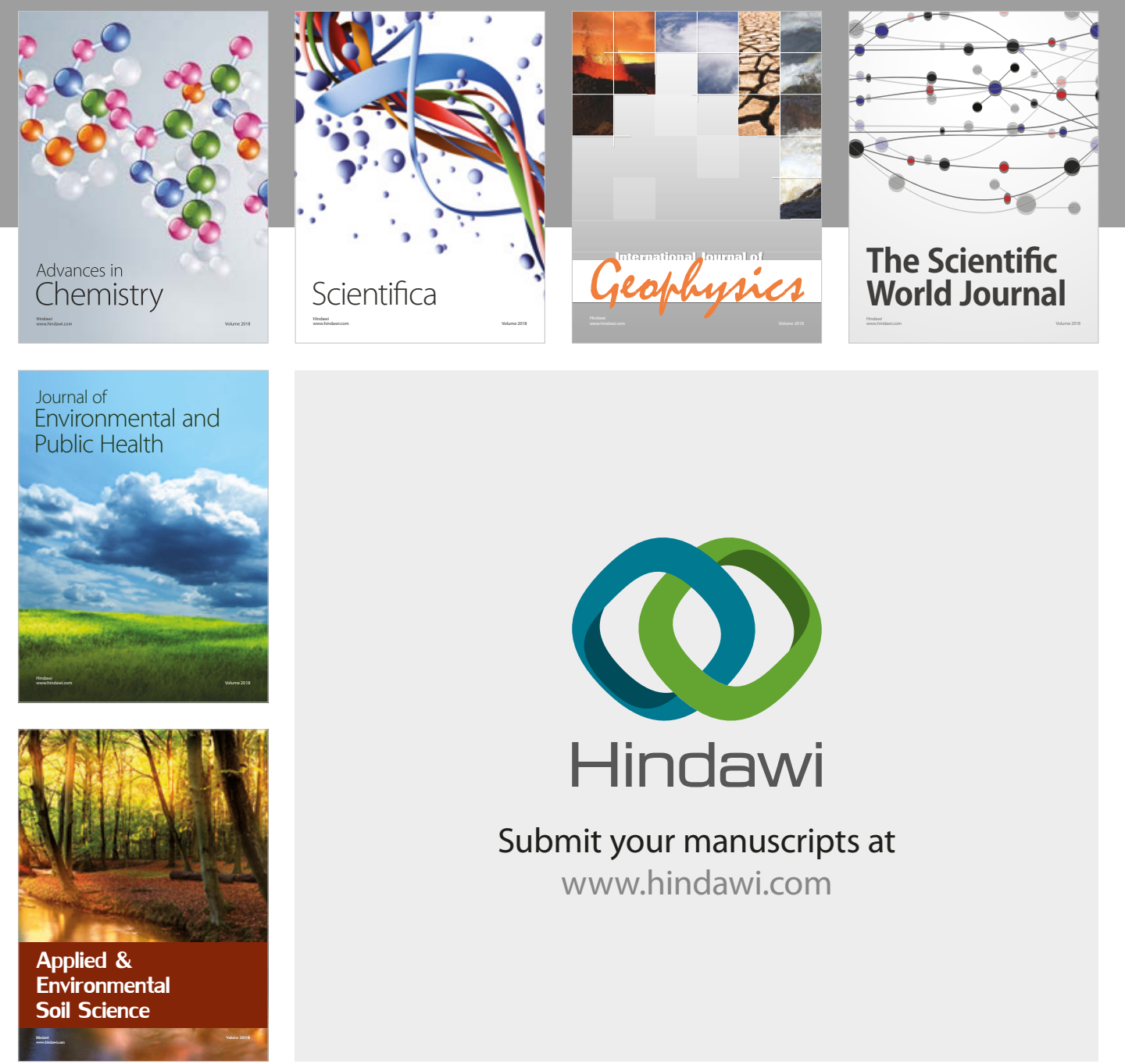

The Scientific

\section{World Journal}
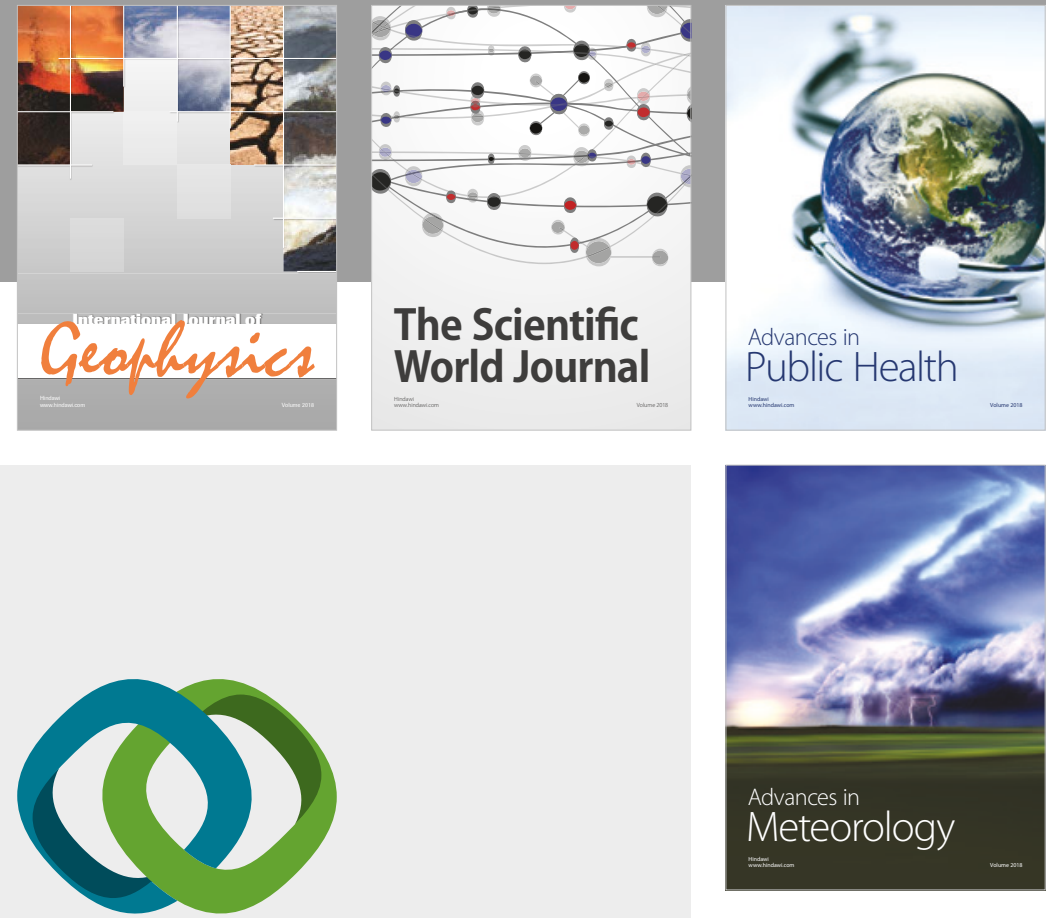

Advan

Public Health

\section{Hindawi}

Submit your manuscripts at

www.hindawi.com
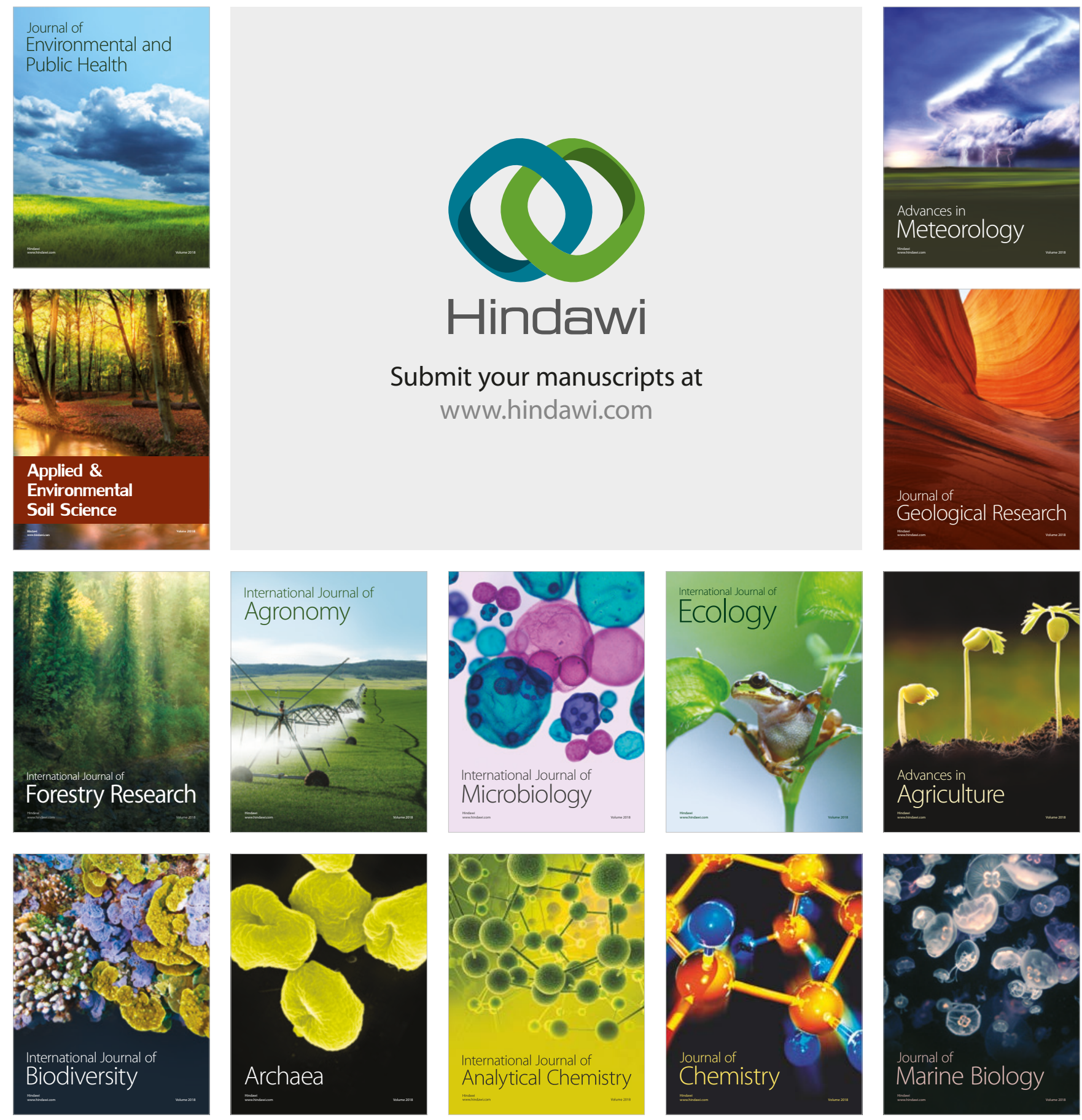